\title{
BIODEGRADABILIDAD DE LA MATERIA ORGÁNICA NATURAL DEL AGUA Y EFECTO DEL OZONO
}

\author{
Francisco Javier Rodríguez Vidal, Antonio Pérez Serrano, Carmen Orozco Barrenetxea,
} $\mathbf{M}^{\mathrm{a}}$ Nieves González Delgado y $\mathbf{M}^{\mathrm{a}}$ Victoria Ibeas Reoyo.

\begin{abstract}
Resumen:
En el presente trabajo se estudia la biodegradabilidad de la materia orgánica natural del agua (MON), constituída fundamentalmente por las sustancias húmicas (ácidos fúlvicos y húmicos), y la influencia del tratamiento de preozonización, mediante ensayos basados en la medida del carbono orgánico disuelto biodegradable (CODB). Los ácidos fúlvicos y húmicos tienen un carácter poco biodegradable, por tratarse de grandes macromoléculas orgánicas poco aptas para ser utilizadas por el metabolismo de los microorganismos acuáticos; el tratamiento de ozonización aumenta la biodegradabilidad de las sustancias húmicas y, en general, de la MON del agua.
\end{abstract}

Palabras clave: biodegradabilidad, sustancias húmicas, tratamientos.

\section{Introducción}

Recientes estudios (LeChevallier, 1992; Van der Kooij, 1992; Ribas, 1991; Van der Wende, 1988; LeChevallier, 1987) han mostrado la existencia de episodios de "rebrotes bacterianos" en las redes de distribución, a pesar de la correcta calidad microbiológica del agua de salida de las plantas potabilizadoras (Bouwer, 1988); tal hecho indica la formación endógena de bacterias en la propia red de distribución. Dichas bacterias no se encuentran generalmente en el agua sino que se presentan asociadas a las paredes de las tuberías (LeChevallier, 1992), formando lo que se denomina una "biopelícula bacteriana"; una biopelícula bacteriana es una capa de microorganismos que en un entorno acuático se unen a un sustrato (la pared interna de las tuberías) gracias a la formación de una matriz orgánica, la cual tiene su origen en la excrección de sustancias extracelulares por parte de las células bacterianas (Frías, 1992; Van der Wende, 1989).

Las bacterias que forman parte de este tipo de biopelículas son, generalmente, organismos heterótrofos y la mayor parte de ellas aerobias; entre ellas se han identificado especies bastante conocidas, como los coliformes (LeChevallier, 1992), pero también otras muchas especies menos comunes, como las pertenecientes a los géneros Flavobacterium, Cytophaga, Xanthomonas, Arthrobacter, Corynebacterium, Bacillus, Aeromonas y Pseudomonas (Van der Kooij, 1982); el mayor problema de salud pública lo ocasionan los organismos potencialmente patógenos, como Legionella, Aeromonas, Pseudomonas (Van der Kooij, 1992). Además, algunas especies como Klebsiella y Enterobacter pueden interferir y ser enumeradas en el test de coliformes (Van der Kooij, 1982; Rittmann, 1984).

Diversos estudios recogidos en la literatura muestran que el cloro no es efectivo en el control de las biopelículas bacterianas, incluso en presencia de grandes cantidades de cloro residual $(3 \mathrm{mg} \mathrm{Cl} / \mathrm{l})$ (LeChevallier, 1990); tales resultados pueden deberse a dos causas principales (Van der Kooij, 1992):

Departamento de Química. Escuela Politécnica Superior. Universidad de Burgos.

Avda. General Vigón s/n. 09006 Burgos. Telf.: 94725 89 37; Fax:947 2589 10; e-mail:qpvito@ubu.es

Artículo recibido el 18 de enero de 1999, recibido de forma revisada el 17 de enero de 2000, y aceptado para su publicación el 10 de febrero de 2000 
- la menor capacidad de acción del cloro frente a biopelículas (bacterias adheridas a una superfície sólida) que frente a bacterias suspendidas en el agua (Herson, 1987; LeChevallier, 1988).

- la presencia de especies bacterianas más resistentes a la acción del cloro en las biopelículas (LeChevallier, 1980; Ridgway, 1982).

Además, no es deseable el empleo de altas dosis de cloro en la red de distribución debido a los problemas relacionados con tal uso: deterioro de las características organolépticas (olores y sabores), aumento en la formación de subproductos de la desinfección (trihalometanos, etc) e incremento en la velocidad de corrosión de los materiales metálicos (Rittmann, 1984). Algunos autores indican que las cloraminas pueden ser más efectivas que el cloro en la penetración a través de la biopelícula bacteriana y su inactivación (LeChevallier, 1992; LeChevallier, 1988; LeChevallier, 1988a); sin embargo, otros autores indican que algunos microorganismos (bacterias nitrificantes) pueden ver favorecida su aparición en presencia de cloro combinado (cloraminas) (Rittmann, 1984; Siddiqui, 1997).

$\mathrm{Al}$ igual que en los ecosistemas acuáticos, se admite que el elemento limitante del crecimiento de los microorganismos que forman parte de la biopelícula es el carbono (Frías, 1992; Van der Kooij, 1992); por lo tanto, la manera más eficaz de evitar la aparición de dicha biopelícula en la red de distribución (lo que se denomina "agua biológicamente estable") es la eliminación previa del carbono orgánico que pueden utilizar dichos microorganismos para su crecimiento. Sin embargo, no toda la materia orgánica presente en el agua puede ser utilizada por las bacterias para su crecimiento; de hecho, la fracción mayoritaria de la misma (las sustancias húmicas) es difícilmente biodegradable (De Laat, 1991; Servais, 1987) y sólo una pequeña parte es utilizable por los microorganismos (Bouwer, 1988; Rittmann, 1984), principalmente compuestos como: aminoácidos, péptidos, ácidos grasos, ácidos hidroxicarboxílicos y carbohidratos. Por tal motivo, parámetros indicadores del contenido total de materia orgánica, como el carbono orgánico total (COT) y la demanda química de oxígeno (DQO), no son buenos indicadores del potencial de aparición de las biopelículas bacterianas en la red de distribución (Van der Kooij, 1992). Es necesaria la caracterización de la fracción de materia orgánica utilizable por los microorganismos, para lo cual se han desarrollado nuevos ensayos, como son el carbono orgánico disuelto biodegradable: CODB (mide la fracción de carbono orgánico disuelto del agua qu puede ser biodegradada por microorganismos heterótrofos) y el carbono orgánico asimilable: COA (mide la fracción de carbono orgánico biodegradable que puede ser convertida en biomasa celular). En el presente trabajo se utiliza el parámetro CODB para evaluar la biodegradabilidad de la MON.

El tratamiento de ozonización del agua, a las dosis habituales de operación en las plantas potabilizadoras, provoca la oxidación parcial de la MON, produciendo compuestos orgánicos que generalmente son más biodegradables que las especies de partida; esto es debido principalmente a que el ozono rompe las grandes macromoléculas húmicas (la fracción mayoritaria de la MON), produciendo fragmentos moleculares más pequeños y mejor asimilables por las bacterias.

\section{Material y métodos}

- Materia orgánica natural (MON): en el presente estudio se han empleado tres tipos de materia orgánica natural: agua natural del Embalse de Úzquiza (Burgos), ácidos fúlvicos naturales (extraídos del Embalse de Úzquiza) y ácidos húmicos comerciales (Aldrich).

- Extracción de las sustancias húmicas: el esquema seguido para la extracción de las sustancias húmicas del agua del Embalse de Úzquiza es el propuesto por Thurman y Malcolm (Thurman, 1981): se hace pasar la muestra de agua acidificada a $\mathrm{pH}=2$ a través de una columna que contiene una resina polimérica no iónica (Amberlita XAD-7), en la cual quedan adsorbidas las sustancias húmicas (sustancias orgánicas hidrofóbicas de alto peso molecular). La elución de las sustancias húmicas de la columna se consigue con $\mathrm{NaOH} 0,1 \mathrm{~N}$ y la posterior diferenciación entre ácidos fúlvicos y húmicos se hace por precipitación de los últimos a $\mathrm{pH}=1$, quedando los ácidos fúlvicos en disolución. Ambas fracciones se separan mediante centrifugación a $8000 \mathrm{rpm}$ y $4^{\circ} \mathrm{C}$ durante 20 minutos.

- Medida del Carbono Orgánico Total (COT): se llevó a cabo mediante un analizador de carbono orgánico total (Shimadzu TOC-5050), el cual está basado en el método de combustión y análisis del gas mediante detector de infrarrojo no dispersivo.

- Ensayos de ozonización: se llevaron a cabo mediante la utilización de un generador de ozono y un reactor de PVC (30 1); el reactor funciona en ré- 
gimen semicontínuo (semi-batch): continuo con respecto al ozono y discontinuo con respecto a la muestra acuosa. La dosis aplicada de ozono se controla variando el tiempo de ozonización, teniendo en cuenta la producción de ozono del generador y el volumen de muestra acuosa utilizado. Una vez ozonizada la muestra a la dosis requerida, se deja reposar (en recipientes cerrados) unas 2 horas aproximadamente, para asegurar la eliminación del ozono residual de la muestra, requisito necesario para la realización de los posteriores ensayos de biodegradación (la presencia de ozono residual en el agua puede oxidar y destruir al carbón activado).

- Ensayos de biodegradación: se realizaron dos ensayos de biodegradación distintos, ambos basados en la medida del carbono orgánico disuelto biodegradable (CODB). En dichos métodos la muestra de agua es inoculada con una población bacteriana, encargada de la biodegradación de la materia orgánica; al finalizar el periodo de incubación determinado, el CODB se determina como la diferencia entre el COD inicial y el final. La medida del COD (Carbono Orgánico Disuelto) consiste en la medida del COT, con el requisito previo de la filtración de la muestra (filtros de $0,45 \mu \mathrm{m}$ ). Los ensayos de biodegradación utilizados fueron los siguientes:

a) Método de Billen-Servais (Servais, 1987):

La muestra de agua objeto de análisis es inoculada con un pequeño volumen (habitualmente el $1 \%$ del volumen de la muestra) de agua natural o de alguna etapa de la secuencia de tratamiento (normalmente, después de la etapa de filtración); dicho inóculo contiene la población bacteriana necesaria para la biodegradación de la materia orgánica y debe ser previamente filtrado $(2 \mu \mathrm{m})$ para eliminar protozoos. Tras el periodo de incubación elegido (normalmente 28 días, en oscuridad y a $20^{\circ} \mathrm{C}$ ), se calcula el CODB como la diferencia entre el COD inicial y el final.

En el presente estudio se utilizó el método de Billen-Servais con ligeras modificaciones: la cantidad de muestra empleada en los ensayos es de 150 ml. y el volumen de inóculo de $5 \mathrm{ml}$. de agua natural del Embalse de Úzquiza. En un primer ensayo preliminar el tiempo de incubación elegido fue de 28 días; basándose en los resultados obtenidos en dicho ensayo se decidió elegir un tiempo de incubación más corto, de 7 días, ya que proporcionaba resultados de CODB lo suficientemente significativos para su análisis. La temperatura de incubación elegida fue de $25^{\circ} \mathrm{C}$. b) Método de Joret-Lévi (Joret, 1986):

Este método es más rápido que el anterior y utiliza como inóculo arena biológicamente activa, es decir, que contiene una población bacteriana; dicha arena usualmente procede de los filtros de las plantas potabilizadoras y antes del ensayo es lavada con agua destilada hasta que no libere COD (procedente de materia orgánica que lleva retenida la arena y que interfiere en el ensayo). La muestra de agua es inoculada con la arena, habitualmente 100 g. arena por cada $300 \mathrm{ml}$. de agua, y se incuba durante 8 días (en algunos casos durante 3-5 días) en oscuridad y a $20^{\circ} \mathrm{C}$. El CODB se calcula como en el caso anterior: la diferencia entre el COD inicial y el final tras el periodo de incubación.

En el presente estudio se utilizó el método de Joret-Levi con ligeras modificaciones: la arena biológicamente activa se produjo en el laboratorio a partir de arena virgen idéntica a la usada en la planta potabilizadora de Arlanzón ( Burgos), la cual fue incubada con agua natural del Embalse de Úzquiza (junto con un aporte periódico de nutrientes de nitrógeno y fósforo) durante tres meses, periodo lo suficientemente largo para asegurar la presencia de población bacteriana en la arena. La cantidad de muestra fue de $150 \mathrm{ml}$. y la cantidad de arena inoculada no se midió en masa sino en volumen: se escogió la cantidad de arena que ocupaba un volumen de $50 \mathrm{ml}$. medido en una probeta; el periodo de incubación elegido fue de 7 días y la temperatura de incubación de $25^{\circ} \mathrm{C}$, para coincidir con el ensayo anterior.

- Ensayos de filtración en columna.

a) Filtración estéril: estos ensayos suponen la utilización de adsorbentes en condiciones estériles, es decir, sin presencia de población microbiana en el lecho adsorbente de la columna (se usa $\mathrm{HgCl}_{2}$ para evitar el crecimiento bacteriano en el lecho). Los ensayos de filtración estéril se realizaron en columnas cromatográficas (con placa porosa en su parte inferior) de $1 \mathrm{~m}$. de longitud y $5 \mathrm{~cm}$. de diámetro interno, las cuales se llenaron hasta la mitad de su longitud $(0,5 \mathrm{~m}$.) con dos tipos de materiales filtrantes: arena (del mismo tipo que la usada en la planta potabilizadora de Arlanzón - Burgos) y carbón activado granular (CAG) de un tamaño de grano similar al de la arena. La muestra de agua se hace pasar a través de la columna, controlando con la llave de paso la velocidad de filtrado, utilizándose en el presente estudio una velocidad lineal de filtrado de aproximadamente $0,75 \mathrm{~m} / \mathrm{h}$, correspondiente a un tiempo de contacto en lecho vacío (EBCT) de unos 40 minutos. 
b) Filtración biológica: la filtración biológica supone la utilización de adsorbentes biológicos, es decir, adsorbentes que contienen una población bacteriana (biopelícula bacteriana); por lo tanto, intervienen dos mecanismos para la eliminación de la materia orgánica: la adsorción y la biodegradación. Dichos adsorbentes biológicos se preparan incubando los adsorbentes vírgenes con agua natural del Embalse de Úzquiza durante un periodo de tres meses. El ensayo de filtración de columna se hace de manera análoga a la descrita en el caso anterior y los adsorbentes utilizados fueron los mismos.

\section{Resultados}

\section{Influencia de la ozonización sobre la biodegradabilidad de la materia orgánica.}

La evolución del CODB, para diversas dosis aplicadas de ozono (0-10 $\mathrm{mg} \mathrm{O}_{3} / \mathrm{mg}$ COT), se muestra en la figura 1 (agua natural del Embalse), la figura 2 (ácidos húmicos comerciales) y la figura 3 (ácidos fúlvicos naturales); para cada dosis de ozono, el CODB se calcula como la diferencia entre el COD resultante tras la ozonización (ya que un ligero porcentaje de $\mathrm{COD}$ se mineraliza hasta $\mathrm{CO}_{2}$ por efecto del ozono) y el COD remanente tras el ensayo de biodegradación. Esta última fracción orgánica resistente a la biodegradación también se denomina CODR (carbono orgánico disuelto refractario) (Ribas, 1997).

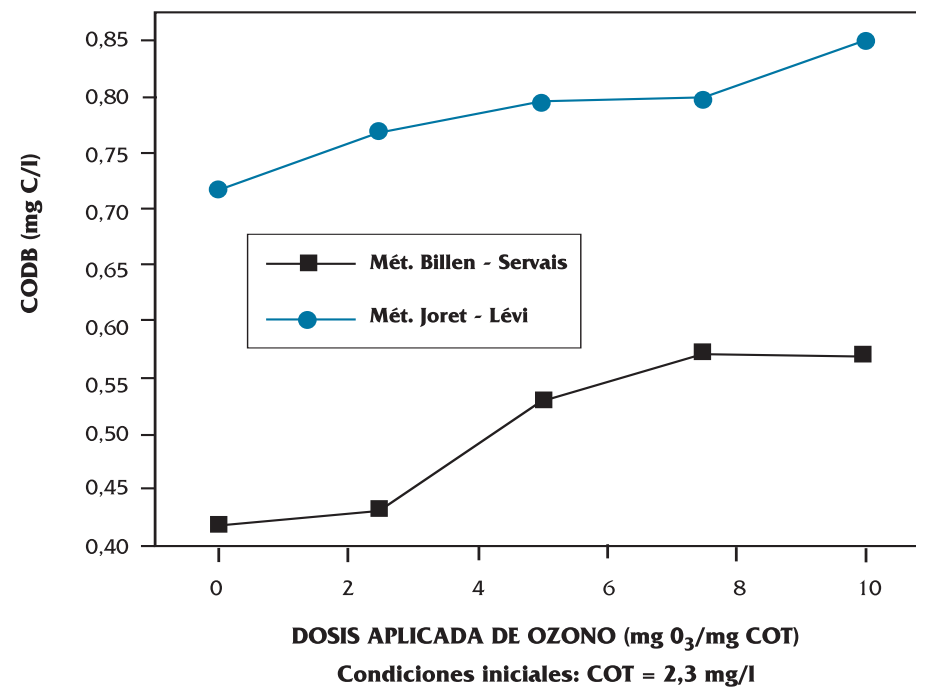

Figura 1. Influencia del ozono sobre la biodegradabilidad de la MON: AGUA NATURAL

La primera observación que se deduce de las gráficas anteriores es que el método de Billen-Servais (inóculo: agua natural) proporciona valores significativamente menores de CODB que el méto-

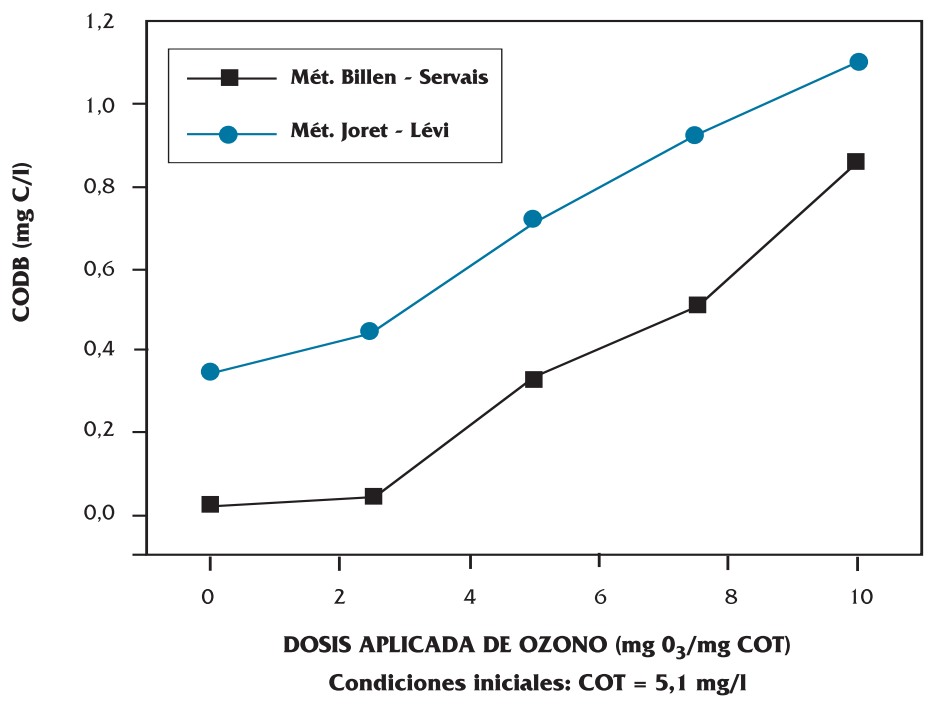

Figura 2. Influencia del ozono sobre la biodegradabilidad de la MON: ÁCIDOS HÚMICOS

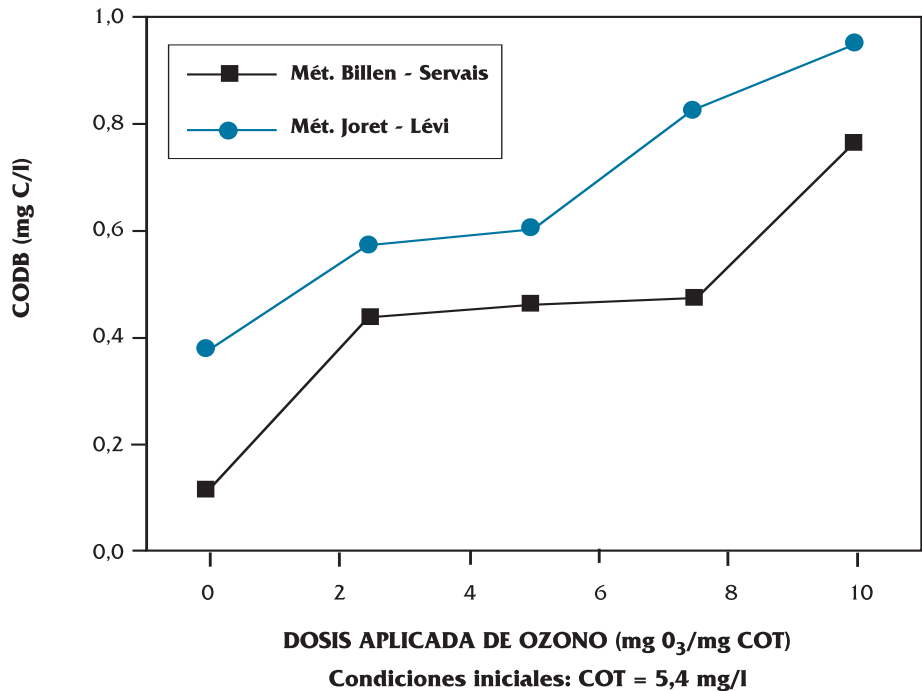

Figura 3. Influencia del ozono sobre la biodegradabilidad de la MON: ÁCIDOS FÚLVICOS

do de Joret-Lévi (inóculo: arena aclimatada) para los tres tipos de MON estudiados; tal resultado indica que la biodegradación llevada a cabo por las biopelículas bacterianas ligadas a un soporte inerte (arena) es más efectiva que la realizada por las bacterias presentes en la solución acuosa, debido fundamentalmente al mayor número de bacterias presentes en la biopelícula (es un entorno más adecuado para el crecimiento bacteriano), aunque también pueden intervenir, en un pequeño porcentaje, fenómenos de adsorción superficial de la MON sobre el soporte (a pesar de usar materiales no adsorbentes) (Huck, 1990). Algunos autores (Cipparone, 1997) han encontrado resultados similares en ensayos análogos de biodegradación y proponen que los ensayos de CODB basados en biopelículas bacteria- 
nas aclimatadas son más útiles que los basados en bacterias presentes en la solución acuosa, ya que los primeros reproducen más fielmente las condiciones de los rebrotes bacterianos en las redes de distribución, los cuales consisten también en biopelículas ligadas a una superfície inerte.

Diversos estudios recogidos en la literatura indican que la ozonización de la materia orgánica natural del agua da lugar a la producción de compuestos más biodegradables (Ribas, 1997; Paode, 1997; AWWA, 1991; Servais, 1987; Van der Kooij, 1982). En las gráficas anteriores se puede observar que el efecto de la ozonización sobre el CODB sigue la misma tendencia en todos los casos: aumento del CODB, y por lo tanto de la biodegradabilidad de la materia orgánica presente, al aumentar la dosis aplicada de ozono. El incremento del CODB es más significativo para los casos de las sustancias húmicas que para el agua natural. Las sustancias húmicas consisten en grandes macromoléculas orgánicas que son, en general, poco biodegradables (De Laat, 1991), por lo que el efecto del ozono (produciendo fragmentos moleculares más pequeños y mejor asimilables por las bacterias) es considerable. Sin embargo, el agua natural presenta aproximadamente un $50 \%$ de sustancias húmicas sobre el contenido orgánico total del agua; el resto de materia orgánica está formada por compuestos de menor tamaño, como ácidos hidrofílicos de bajo peso molecular, bases hidrofílicas, aminoácidos, etc, los cuales son compuestos ya de por sí biodegradables, por lo que el efecto del ozono en este caso es menos significativo.

Debido a que en los tres tipos de MON se emplearon concentraciones iniciales diferentes de COT, los valores absolutos de CODB no se pueden comparar directamente a partir de las gráficas anteriores; la comparación entre ellas se lleva a cabo estudiando la relación CODB/COT (es decir, el porcentaje de CODB en cada caso). Tal comparación se muestra en la Tabla 1, donde se observa que pa- ra las muestras sin ozonizar, el agua natural del embalse es la que presenta el mayor carácter biodegradable (por las razones expuestas anteriormente); las sustancias húmicas presentan una baja biodegradabilidad, presentando valores ligeramente superiores los ácidos fúlvicos, los cuales son macromoléculas de menor tamaño que los ácidos húmicos.

Los valores de BDOC encontrados en el presente estudio para el agua natural del embalse se encuentran dentro del rango de valores descritos en la literatura (Servais, 1987).

Al ir incrementando la dosis aplicacada de ozono, tanto las sustancias húmicas puras como el agua natural (esta última posee un contenido del $50 \%$ en sustancias húmicas, de las cuales un $90 \%$ corresponde a ácidos fúlvicos y sólo un $10 \%$ a ácidos húmicos), aumentan su carácter biodegradable; el efecto del ozono parece más significativo sobre los ácidos húmicos, ya que a partir de la dosis de 5 $\mathrm{mg} \mathrm{O}_{3} / \mathrm{mg}$ COT presentan porcentajes de CODB superiores a los de los ácidos fúlvicos (inicialmente más biodegradables). En conjunto, para la dosis de ozono aplicada más alta $\left(10 \mathrm{mg} \mathrm{O_{3 }} / \mathrm{mg} \mathrm{COT}\right)$, los ácidos húmicos presentan el mayor aumento de CODB ( $\triangle \mathrm{CODB} \sim 18 \%$ ), seguido de los ácidos fúlvicos $(\triangle \mathrm{CODB} \sim 11 \%)$ y por último el agua natural $(\triangle \mathrm{CODB} \sim 8,6 \%)$.

\section{Ensayos de filtración en columna.}

La manera más fácil de evitar la presencia de carbono orgánico biodegradable en la red de distribución es su eliminación previa en las plantas potabilizadoras mediante tratamientos biológicos; debido a las bajas concentraciones de compuestos orgánicos biodegradables en las aguas naturales destinadas a consumo humano, el método más eficaz para llevar a cabo su biodegradación y eliminación es la utilización de "biofiltros" (filtros biológicamente activos), consistentes en un medio físico sobre el que se desarrolla una biopelícula bacteriana

Tabla 1. Influencia del ozono en la producción de CODB (relación CODB/COT, en \%)

\begin{tabular}{|c|c|c|c|c|c|c|}
\hline \multirow{3}{*}{$\begin{array}{c}\text { Dósis Aplicada } \\
\text { de Ozono } \\
\text { (mg } \mathrm{O}_{3} / \mathrm{mg} \text { COT) }\end{array}$} & \multicolumn{6}{|c|}{ Porcentaje de CODB (\%) } \\
\hline & \multicolumn{2}{|c|}{ Agua Natural } & \multicolumn{2}{|c|}{ Ácidos Húmicos } & \multicolumn{2}{|c|}{ Ácidos Fúlvicos } \\
\hline & (1) & (2) & (1) & (2) & (1) & (2) \\
\hline 0,0 & 18,0 & 30,8 & 0,0 & 6,7 & 2,1 & 7,0 \\
\hline 2,5 & 18,8 & 33,5 & 0,1 & 9,2 & 8,2 & 10,7 \\
\hline 5,0 & 23,7 & 35,5 & 6,8 & 15,0 & 8,8 & 11,5 \\
\hline 7,5 & 26,0 & 36,3 & 10,6 & 19,5 & 9,1 & 16,0 \\
\hline 10 & 26,6 & 39,5 & 18,3 & 23,8 & 14,9 & 18,6 \\
\hline
\end{tabular}

(1) Método de Billen-Servais

(2) Método de Joret-Lévi 
adherida superficialmente al mismo (Paulsen, 1997) y que es la encargada de eliminar el CODB. El material soporte de los filtros se puede clasificar en dos categorías principales: no adsorbente (arena, grava) y adsorbente (carbón activado granular: CAG); a la combinación de los mecanismos de adsorción y biodegradación en el CAG se le ha denominado CAB (carbón activado biológico). La mayoría de los estudios indican una mayor eficacia de los filtros de CAG sobre los no adsorbentes (LeChevallier, 1992; AWWA, 1991). Además, la mayoría de los estudios indican que el tiempo necesario para que se desarrolle la capacidad biológica sobre los filtros de CAG es de unos 5-20 días, en condiciones normales de operación (AWWA, 1991; Krasner, 1993), un tiempo sensiblemente menor que el necesario en los filtros de materiales no adsorbentes (Urfer, 1997).

Para comprobar la extrapolación de los resultados obtenidos en el Apartado anterior a las condiciones reales de operación de las plantas potabilizadoras, se realizaron en el laboratorio ensayos de filtración en columna, los cuales suponen una aproximación más fiable de los resultados que los ensayos estáticos de biodegradación. La materia orgánica objeto de estudio han sido los ácidos húmicos comerciales, ya que se encuentran disponibles en el laboratorio en cantidad suficiente para preparar las disoluciones de partida a unas concentraciones iniciales lo suficientemente altas como para observar efectos significativos en los experimentos.

Los resultados de los ensayos de filtración en columna se muestran en la figura 4; la concentra-

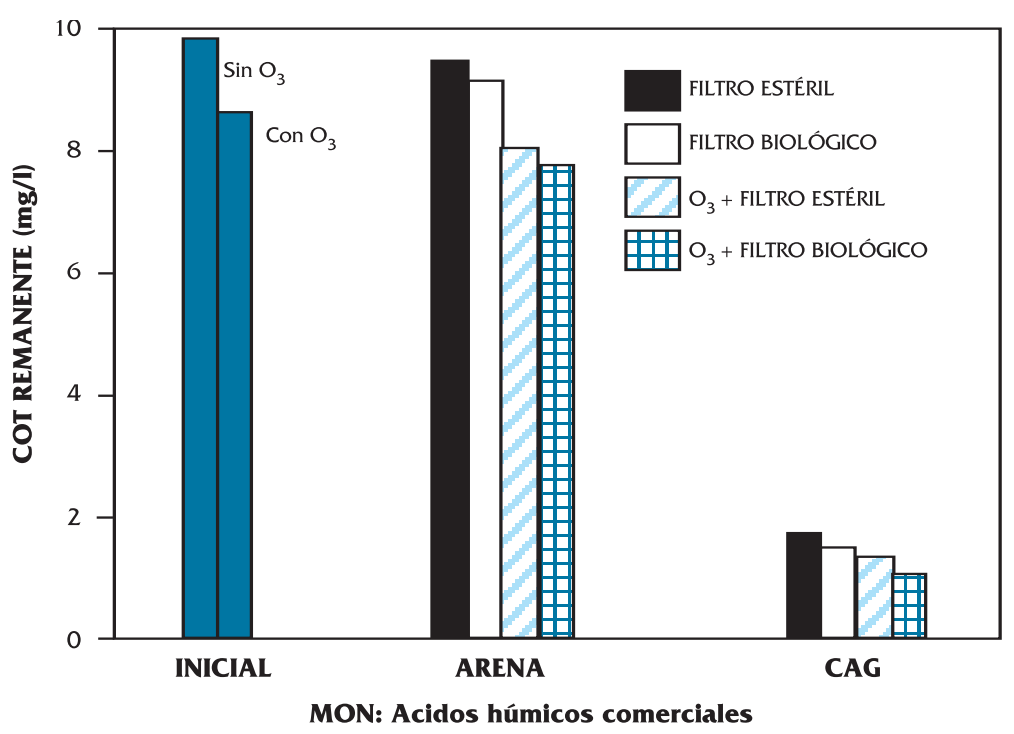

Figura 4. Eficacia de los distintos tipos de filtros en la eliminación de COT ción inicial de la disolución de ácidos húmicos a tratar es de 9,78 mg/l COT, y en los casos de preozonización, la dosis aplicada de ozono es de $10 \mathrm{mg}$ $\mathrm{O}_{3} / \mathrm{mg}$ COT, la cual reduce la concentración de COT hasta un valor de $8,6 \mathrm{mg} / \mathrm{l}$, lo que supone una eliminación de COT del $12 \%$ por efecto de la ozonización (los datos de los filtros que reciben muestras preozonizadas incluyen dicho efecto de eliminación parcial de COT por parte del ozono). El parámetro representado en la gráfica es la cantidad de COT remanente que queda en el efluente filtrado.

Los filtros estériles sólo eliminan COT mediante el mecanismo de adsorción, mientras que en los filtros biológicos se suma el mecanismo de biodegradación al de adsorción; para cada pareja de filtros estéril/biológico, la diferencia entre ambos representa el porcentaje de COT eliminado mediante biodegradación. La ligera eliminación de COT observada en el filtro de arena estéril (un material calificado de no adsorbente) se atribuye a una mínima adsorción superficial de los ácidos húmicos sobre la arena; la eliminación de COT en el filtro estéril de arena que recibe la muestra preozonizada es la combinación del efecto de la ozonización (mineralización de parte de la materia orgánica) y la mínima adsorción superficial comentada.

Lógicamente, la filtración con CAG presenta unas reducciones de COT mucho mayores que la arena, debido al gran carácter adsorbente del CAG con respecto a las sustancias húmicas.

En la figura 4 se observa también que los filtros biológicamente activos presentan en todos los casos una eficacia ligeramente superior a los filtros estériles en cuánto a eliminación de COT; tal efecto se atribuye al mecanismo adicional de biodegradación que tiene lugar en los filtros biológicos. La eficacia relativa de los distintos filtros en la eliminación de COT se muestra en la Tabla 2, donde la columna "Diferencia" (DIF) indica la diferencia entre el filtro biológico y el estéril; tal diferencia representa la contribución del mecanismo de biodegradación en cada caso. Los datos de las muestras "con preozonización" incluyen el efecto de mineralización parcial de la materia orgánica por parte del ozono $(\sim 12 \%)$.

Se pueden hacer las siguientes observaciones principales:

- En todos los casos, se obtiene una mayor eficacia en la eliminación global de 
Tabla 2. Porcentaje de eficacia (\%) de los filtros en la eliminación de COT

\begin{tabular}{|c|c|c|c|c|c|c|}
\hline \multirow{2}{*}{ Tipo de filtro } & \multicolumn{3}{c|}{ Porcentaje de COT eliminado (\%) } \\
\cline { 2 - 7 } & $\begin{array}{c}\text { Filtro preozonización } \\
\text { estéril }\end{array}$ & $\begin{array}{c}\text { Filtro } \\
\text { biológico }\end{array}$ & Diferencia & $\begin{array}{c}\text { Filtro } \\
\text { estéril }\end{array}$ & $\begin{array}{c}\text { Filtro } \\
\text { biológico }\end{array}$ & Diferencia \\
\cline { 2 - 8 } & 3,3 & 6,3 & $\mathbf{3 , 0}$ & 17,4 & 21,3 & $\mathbf{3 , 9}$ \\
\hline ARENA & 82,4 & 85,3 & $\mathbf{2 , 9}$ & 86,9 & 90,0 & $\mathbf{3 , 1}$ \\
\hline
\end{tabular}

MON: Ácidos Húmicos. La columna "Diferencia” indica la contribución de la biodegradación.

COT en los procesos de filtración-adsorción precedidos por el tratamiento de ozonización.

- Como se ha comentado anteriormente, los filtros biológicos presentan una eficacia ligeramente superior a los filtros estériles: las diferencias entre filtros biológicos y filtros estériles oscilan entre un 3-4 \%, presentando resultados muy similares en todos los experimentos, por lo que en el presente caso los biofilms formados sobre materiales adsorbentes (CAG) y no adsorbentes (arena) presentan eficacias similares en la eliminación de COT.

- Con respecto a la influencia de la preozonización, se observan ligeros aumentos en la eliminación de COT (para ambos tipos de filtro: arena y CAG) mediante el mecanismo de biodegradación en las muestras preozonizadas (comparación entre las columnas "Diferencia" para los casos "sin preozonización" y "con preozonización”), aunque dichas diferencias no son tan significativas como las que cabría esperar en base al aumento del CODB (18\%) con la ozonización (véase tabla 1). Tal diferencia puede ser debida a un insuficiente tiempo de contacto ( 40 minutos) entre la materia orgánica y la biopelícula bacteriana en los filtros biológicos, en contraste con el tiempo de contacto utilizado en los ensayos de CODB (7 días).

\section{Conclusiones}

-El método de Billen-Servais (inóculo bacteriano: agua natural) proporciona valores significativamente menores de CODB que el método de Joret-Lévi (inóculo bacteriano: arena aclimatada) para los tres tipos de materia orgánica natural estudiados.

- El agua natural del embalse es la que presenta el mayor carácter biodegradable, mientras que las sustancias húmicas presentan una baja biodegradabilidad, mostrando valores ligeramente superiores los ácidos fúlvicos, los cuales son macromoléculas de menor tamaño que los ácidos húmi- cos y por lo tanto, más fácilmente asimilables por las bacterias.

- El efecto de la ozonización sobre el CODB sigue la misma tendencia en todos los casos: aumento del CODB, y por lo tanto de la biodegradabilidad de la materia orgánica presente, al aumentar la dosis aplicada de ozono. El incremento del CODB es más significativo para los casos de las sustancias húmicas que para el agua natural.

- Los filtros biológicos presentan una eficacia ligeramente superior en la eliminación de materia orgánica que los filtros estériles, debido al mecanismo adicional de biodegradación que se da en los primeros; esta diferencia se mantiene, con muy ligeros aumentos, en el caso de aguas preozonizadas.

\section{Referencias}

AWWA (American Waters Works Association) Research Foundation \& Compagnie Générale des Eaux (1991). Ozone in Water Treatment: Application and Engineering. Editado por Langlais,B; Reckhow,A; Brink,D. Ed: Lewis Publishers.

Bouwer, E.J. et al (1988). Biological Processes in Drinking Water Treatment. Jour. AWWA., 80:82.

Cipparone, L.A. et al (1997). Ozonation and BDOC Removal: Effect on Water Quality. Jour. AWWA., 89:2:84.

De Laat, J. et al (1991). Influence d'une Preozonation sur l'Adsorbabilité et la Biodegradabilité des Substances Humiques d'Origine Aquatique et sur les Performances del Filtres de Charbon Actif en Grains. Wat. Res., 25:2:151.

Frías, J. et al (1992). El Control del Carbono Orgánico Biodegradable en el Proceso de Potabilización de Aguas. RETEMA, Julio-Agosto:93.

Herson, D.S. et al (1987). Attachment as a Factor in the Protection of Enterobacter cloacae. Appl. Environ. Microbiol. 53:1178.

Huck, P.M (1990). Measurement of Biodegradable Organic Matter and Bacterial Growth Potential in Drinking Water. Jour. AWWA., July:78. 
Joret, J.C. et al (1986). Méthod Rapide d'Evaluation du Carbone Eliminable des Eaux par Voie Biologique. Trib. Cebedeau, 510:39:3.

Krasner, S.W. et al (1993). Testing Biologically Active Filters for Removing Aldehydes formed during Ozonation. Jour. AWWA., May:62.

LeChevallier, M.W. et al (1980). Enumeration and Characterization of Standard Plate Count Bacteria in Chlorinated and Raw Water Supplies. Appl. Environ. Microbiol.,40:922.

LeChevallier, M.W. et al (1987). Examination and Characterization of Distribution System Biofilms. Appl. Envir. Microbiol., 53:2714.

LeChevallier, M.W. et al (1988). Factors Promoting Survival of Bacteria in Chlorinated Water Supplies. 1988. Appl. Envir. Microbiol., 54:649.

LeChevallier, M.W. et al (1988a). Inactivation of Bacterial Biofilms. Appl. Envir. Microbiol., 54:2492.

LeChevallier, M.W. et al (1990). Disinfection of Biofilms in a Model Distribution System. Jour. AWWA., 82:7:87.

LeChevallier, M.W. et al (1992). Evaluating the Performance of Biologically Active Rapid Filters. Jour. AWWA., April:136.

Paode, R.D. et al (1997). Predicting the Formation of Aldehydes and BOM. Jour. AWWA., June:79.

Paulsen, J.E. et al (1997). Biofilm Morphology in Porous Media: a Study with Microscopic and Image Techniques. Wat. Sci. Technol., 36:1:1.

Ribas, F. et al (1991). A New Dynamic Method for the Rapid Determination of the Biodegradable Dissolved Organic Carbon in Drinking Water. Jour. Appl. Bacteriol., 71:371.

Ribas, F. et al (1997). Efficiency of various Water Treatment Processes in the Removal of Biodegradable and Refractory Organic Matter. Wat. Res., 31:3:639.

Ridgway, H.F. et al (1982). Chlorine Resistence Paterns of Bacteria from Two Drinking Water Distribution Systems. Appl. Environ. Microbiol., 44:972.

Rittmann, B.E. et al (1984). Achieving Biologically Stable Drinking Water. Jour. AWWA., October:106.

Servais, P. et al (1987). Determination of the Biodegradable Fraction of Dissolved Organic Matter in Waters. Wat. Res., 21:4:445.

Siddiqui, M. et al (1997). Ozone Enhanced Removal of Natural Organic Matter from Drinking Water Sources. Wat. Res., 31:12:3098.

Thurman, E.M. et al (1981). Preparative Isolation of Aquatic Humic Substances. Environ. Sci \& Technol., 15:4:463.

Urfer, D. et al (1997). Biological Filtration for BOM and Particle Removal: a critical Review. Jour. AWWA., December:83.

Van der Kooij, D. et al (1982). Determining the Concentration of Easily Assimilable Organic Carbon in Drinking Water. Jour. AWWA., October:540.
Van der Kooij, D. et al (1992). Assimilable Organic Carbon as an Indicator of Bacterial Regrowth. Jour. AWWA., February:57.

Van der Wende, E. et al (1988). Bacterial Growth in Water Distribution Systems. Wat. Sci. Technol., 20:521.

Van der Wende, E. et al (1989). Biofilms and Bacterial Drinking Water Quality. Wat. Res., 23:1313. 